\title{
7 Predictive Risk Mapping of Water Table Depths in a Brazilian Cerrado Area
}

\author{
R. L. Manzione, M. Knotters, G. B. M. Heuvelink, \\ J. R. Von Asmuth, and G. Câmara
}

\section{CONTENTS}

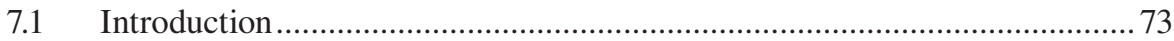

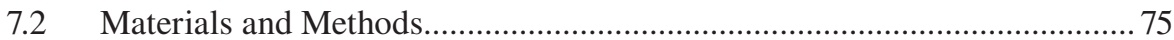

7.2.1 Study Area-The Jardim River Watershed ....................................... 75

7.2.2 Modeling Water Table Depths_-The PIRFICT Model........................76

7.2.3 Uncertainty Measures_-Simulating Water Table Depths ...................79

7.2.4 Risk Mapping—Regionalizing Simulated Water Table Depths ......... 81

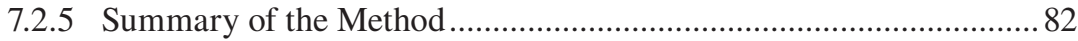

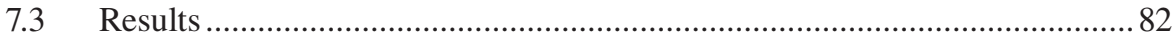

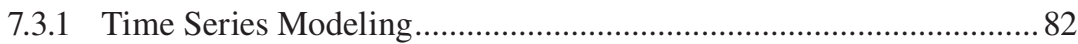

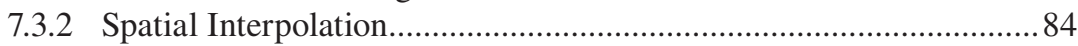

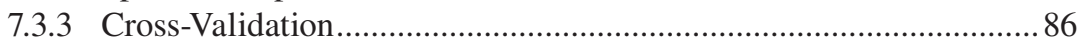

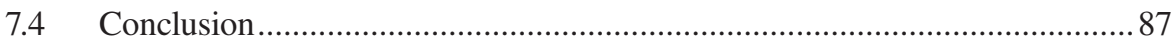

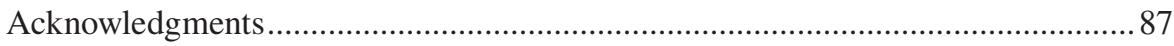

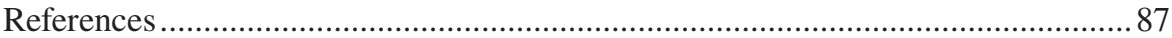

\subsection{INTRODUCTION}

The Brazilian Cerrados extend from the northern margins of the Amazon rain forests to outliers on the southern borders of the country with extensions into Paraguay and Bolivia. Before recent human disturbances, Cerrados probably covered well over 2 million $\mathrm{km}^{2}$, equivalent to 23\% of the Brazilian territory (Jepson, 2005). The Cerrados are woody savannas, which vary from nearly treeless grasslands to what is almost a woodland of semideciduous trees (Furley, 1999). The structure and physiognomy of the Cerrados reflect climatic and other environmental variables. The total annual rainfall over the central area of Brazilian savannas ranges from 1300 to $1600 \mathrm{~mm}$, concentrated in six to seven months between October and April. The rest of the year is characterized by a pronounced dry season. So, natural vegetation has developed adaptations to the seasonal wet rainfall, acid soils, and aluminium toxicity, and features protective devices against fire. Plants metabolize throughout the year, drawing on soil water reserves, and can withstand short-lived fires. 
The expansion of modern agriculture over the past three decades and the establishment of large-scale ranches have affected the characteristic landscape and ecosystem of the Cerrados. These areas became Brazil's most important grain belt, facing deforestation rates much higher than in the Amazon rain forest (Oliveira et al., 2005). A complex wood/grass ecosystem was substituted by shallow-rooted monocultures, which are less well adapted to drought. Their need of water supply by irrigation techniques is likely to change the hydrological system (Klink and Moreira, 2002). With irrigation increasing, lowering of the water table occurs, and so risks of water shortage appear. The preservation of these resources is important because the Cerrado presents itself as an important receiver, keeper, and disperser of water to the three main hydrographic basins of the country (Amazon Basin, Prata Basin, and São Francisco Basin). The negative impact to its environment might be reflected in other Brazilian biomes.

Knowledge about the spatio-temporal dynamics of the water table is important to optimize and balance the interest of economical and ecological land use purposes (Von Asmuth and Knotters, 2004). In hydrology, water table dynamics are modeled in several ways. Many authors refer to transfer function-noise (TFN) models to describe the dynamic relationship between precipitation and water table depths (Box and Jenkins, 1976; Hipel and McLeod, 1994; Tankersley and Graham, 1994; Van Geer and Zuur, 1997). Basically, these models can be seen as multiple regression methods, where the system is seen as a black box that transforms series of observations on the input (the explanatory variables) into a series of output variables (the response variables). The parameters of time series models address the temporal variation of the water table depths, while the spatial component can be accessed by regionalizing the outputs using ancillary information related to the physical basis of these models (Knotters and Bierkens, 2000, 2001). This approach can be used to describe the spatio-temporal variation of the water table depths. It is assumed that the spatial differences in water table dynamics are determined by the spatial variation of the system properties, while its temporal variation is driven by the dynamics of the input into the system.

To link the response characteristics of the water table system to the dynamic behavior of the input, Von Asmuth et al. (2002) presented a method based on the use of a transfer function-noise model in continuous time, the so-called PIRFICT model. An important advantage of the PIRFICT model as compared to discrete-time TFN models is that it can deal with input and output series that have different observation frequencies and irregular time intervals. Using a time series model it is possible to simulate over periods without observations, as long as data on explanatory series are available. For instance, long series (say 30 years' length) on precipitation and evapotranspiration can be assumed to represent the prevailing climatic conditions (Knotters and Van Walsum, 1997). Alternatively, series generated by climatic models might be applied as inputs to the PIRFICT model. From the simulated realizations, statistical characteristics of future water table dynamics can be calculated, such as mean, standard deviation, and limits of prediction.

The aim of this study is to estimate and map the expected water table depths in a watershed located at the Brazilian Cerrados. These estimations are made for a 
specific date in any future year, given the prevailing hydrological and climatic conditions, in order to support decision making in long-term water policy and indicate areas with potential risks of future water shortage and shallow water table depths. In addition, the uncertainty associated with the estimated water table depth is quantified simulating realizations of the stochastic processes.

\subsection{MATERIALS AND METHODS}

\subsubsection{Study Area-The Jardim River Watershed}

The Jardim River watershed is a representative Cerrado area in the eastern part of the Brazilian Federal District., latitudes $15^{\circ} 40^{\prime} \mathrm{S}$ and $16^{\circ} 02^{\prime} \mathrm{S}$ and longitudes $47^{\circ} 20^{\prime} \mathrm{W}$ and $47^{\circ} 40^{\prime} \mathrm{W}$. The dry and wet seasons are well defined, with the rainfall concentrated between October and April. During the past years, almost all natural vegetation of the area was replaced by agricultural crops, and the use of irrigation systems has substantially increased in this region during the past years. The main cultivations in the area are soybeans, cotton, and corn crops, as well as pasture and horticultural crops. To monitor the water table depths, 37 wells were drilled (Figure 7.1). The locations were selected purposively, to cover the range of soil types in the area (Lousada, 2005). The water table was observed semimonthly from October 11, 2003 until October 06,2006 , resulting in series of 50 more or less regularly spaced semimonthly observations, during a period of 1092 days. Series of 33 years' length of precipitation and potential evapotranspiration were available from a climate station close to the basin. The period covered is from 1974 until 1996 with a monthly frequency, and from 1996 until March 2007 with a daily frequency. Ancillary information related to local geomorphology was derived from a digital elevation model (Figure 7.1) with $15 \mathrm{~m}$ resolution (Lousada, 2005).
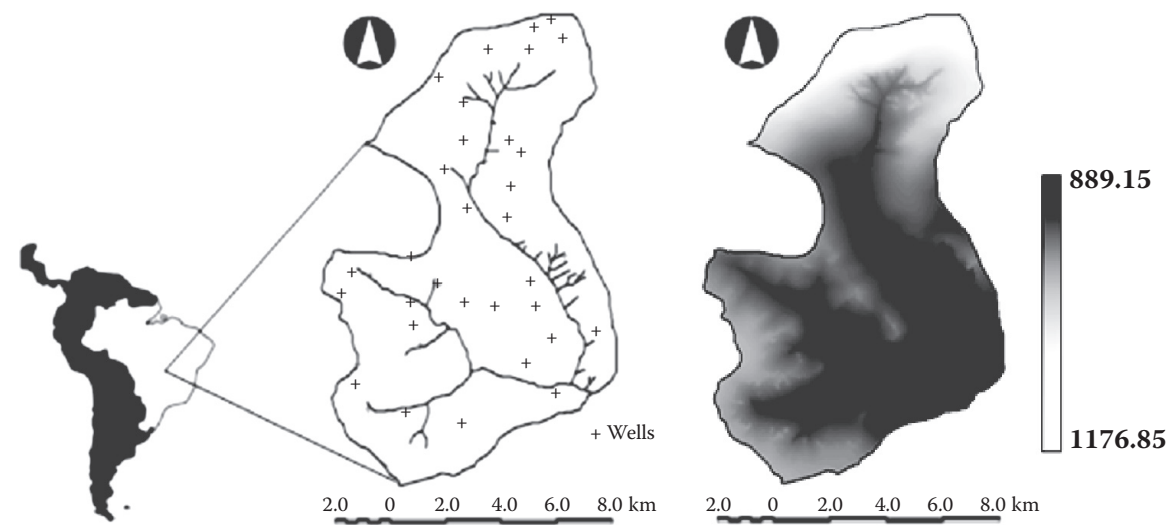

FIGURE 7.1 Jardim River watershed and location of the observation wells (+) (left) and the Digital Elevation Model (right). 


\subsubsection{Modeling Water Table Depths-The Pirfict Model}

The behavior of linear input-output systems can be completely characterized by their impulse response (IR) function (Ziemer et al., 1998; Von Asmuth et al., 2002). The response of water table depth to impulses of precipitation series can be modeled by a transfer function-noise (TFN) model (Box and Jenkins, 1976; Hipel and McLeod, 1994; Von Asmuth and Knotters, 2004). For water table depths, the dynamic relationship between precipitation and water table depth can also be described using physical mechanistic groundwater flow models. However, by using much less complex TFN models, predictions of the water table depth can be obtained that are often as accurate as those obtained by physical mechanistic modeling (Von Asmuth and Knotters, 2004).

The basic idea behind TFN modeling is to split the observed series (output) into a sum of transfer components related to known causes (inputs) that influence the temporal variation of the output and an unknown noise component. TFN models are often applied to distinguish between natural and man-induced components of groundwater series (Van Geer and Zuur, 1997). In TFN models one or more deterministic transfer components and a noise component are distinguished. These components are additive. Each transfer component describes the part of the water table depth that can be explained from an input by a linear transformation of a time series of this input. The noise component describes the autoregressive structure of the differences between the observed water table depths and the sum of the transfer components. The input of the noise model is a series of independently and identically distributed disturbances with zero mean, and finite and constant variance, i.e., white noise. The PIRFICT model, introduced by Von Asmuth et al. (2002), is a specific type of TFN model and an alternative to discrete-time TFN models. In the PIRFICT model a block pulse of the input is transformed into an output series by a continuoustime transfer function. The coefficients of this function do not depend on the observation frequency. The following single-input continuous TFN model can be used to model the relationship between water table dynamics and precipitation surplus/ deficit. For the simple case of a linear, undisturbed phreatic system that is influenced by precipitation surplus/deficit only (Von Asmuth et al., 2002),

$$
\begin{gathered}
h(t)=h^{*}(t)+d+r(t) \\
h^{*}(t)=\int_{-\infty}^{t} p(\tau) \theta(t-\tau) \partial \tau \\
r(t)=\int_{-\infty}^{t} \phi(t-\tau) \partial W(\tau)
\end{gathered}
$$

where:

$h(t)=$ observed water table depth at time $t[T]$;

$h^{*}(t)=$ predicted water table depth at time $t$ attributed to the precipitation surplus/deficit, relative to $d[L]$; 


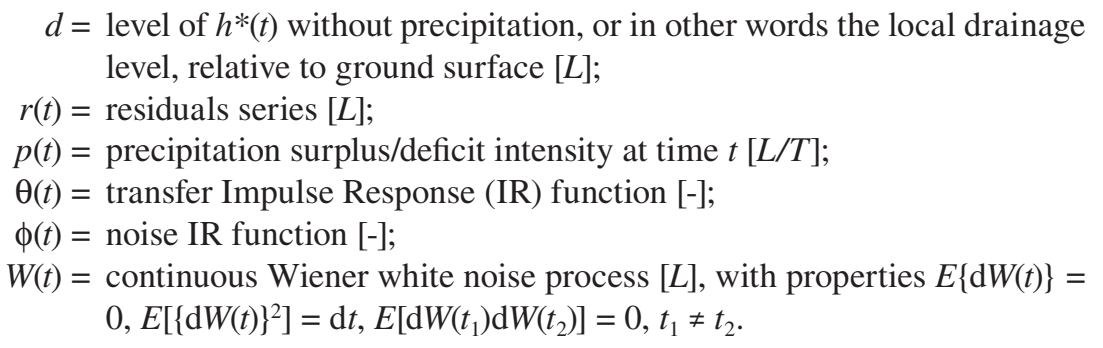

The local drainage level $d$ is obtained from the observations as follows:

$$
d=\frac{\sum_{i=0}^{N} h\left(t_{i}\right) \sum_{i=0}^{N} h^{*}\left(t_{i}\right)}{N}-\frac{\sum_{i=0}^{N} r\left(t_{i}\right)}{N}
$$

with $N$ the number of water table depth observations.

TFN models are identified by choosing mathematical functions that describe the IR and the autoregressive structure of the noise. This identification can be done in two ways: first, iteratively, using correlation structures in the available data and model diagnostics, and, second, physically, based on insight into the behavior of the analyzed system. Here, the second approach is followed. $\theta(t)$ is a Pearson type III distribution function (PIII df; Abramowitz and Stegun, 1964). Because of its flexible nature, this function adequately models the responses of a broad range of groundwater systems. Under the assumption of linearity, the deterministic part of the water table dynamics is completely determined by the IR function moments. In this case, based on Von Asmuth et al. (2002), the parameters can be defined as

$$
\begin{gathered}
\theta(t)=A \frac{a^{n} t^{n-1} \mathrm{e}^{-a t}}{\Gamma(n)} \\
\phi(t)=\sqrt{2 \alpha \sigma_{r}^{2}} \mathrm{e}^{-\alpha t}
\end{gathered}
$$

where $A, a, n$, are the parameters of the adjusted curve; $\Gamma(n)$ is the Gamma function; $\alpha$ determines the decay rate of $\emptyset(t)$; and $\sigma_{r}^{2}$ is the variance of the residuals.

Equation 7.5 and its parameters have a physical meaning that is described in Von Asmuth and Knotters (2004). The physical basis of the PIII df lies in the fact that it describes the transfer function of a series of linear reservoirs (Nash, 1958). The parameter $n$ denotes their number and $a$ equals the inverse of the reservoir coefficient normally used. As Knotters and Bierkens (2000) explain, a single linear reservoir (a PIII df with $n=1$ ) equals a simple physical model of a one-dimensional soil column, discarding lateral flow and the functioning of the unsaturated zone. The extra parameter $A$ is necessary because in the case of Equation 7.5, where a precipitation and evapotranspiration series are transformed into a water table depths series, the law of conservation of mass does not apply. 
The PIII df has been shown to be able to model fluctuations of water table closely and comparably to the Box-Jenkins TFN models with many more parameters (Von Asmuth et al., 2002). The parameter $A$ is related to the local drainage resistance (the area of the IR function equals the ratio of the mean height of the water table to the mean water table recharge), while $A a$ is determined by the storage coefficient of the soil and $n$ as the convection and dispersion time of the precipitation through the unsaturated zone. However, care should be taken when interpreting the parameters of the PIII df, or any other time series model for that matter, in the physical sense, because of their lumped and empirical nature (Von Asmuth and Knotters, 2004).

After the selection of an IR function that represents the underlying physical process, the available time series have to be transformed to continuous series. First, in order to characterize the variability of precipitation and evaporation, we rely on a simple but effective method to estimate the average precipitation surplus intensity and its annual amplitude. When precipitation surplus data are only available at discrete intervals, the continuous series $p(\tau)$ cannot be reconstructed exactly, but it can be approximated by assuming that the distribution of $p(\tau)$ is uniform during the period $t_{p b}$ to $t_{p e}$ (Ziemer et al., 1998). The average level of the precipitation surplus is obtained as

$$
\bar{p}=\frac{\int_{p b}^{p e} p(\tau) \partial \tau}{t_{p e}-t_{p b}}
$$

with $t_{p b}$ and $t_{p e}$ denoting the start and end of the period over which the meteorological characteristics are calculated. Next, time is split into year $Y$ and the Julian day $D$, and the precipitation surplus is averaged over $Y$, which effectively filters out its yearly course:

$$
\tilde{p}(D)=\frac{\sum_{Y_{p b}}^{Y_{p e}} p(Y, D)}{Y_{p e}-Y_{p b}}, \quad 1 \leq D \leq 365
$$

Because the temperature largely determines the annual evaporation cycle and is more or less harmonic, so is the precipitation surplus, and the annual amplitude can be obtained by matching a sine to the yearly course (Von Asmuth and Knotters, 2004).

Using Equation 7.6, the transfer model (Equation 7.2) can be evaluated using a block response (BR) function $\Theta(t)$. The BR function can be obtained by convoluting the IR function with a block pulse of precipitation surplus with unit intensity over a period $\Delta t$, as follow:

$$
\Theta(t)=\int_{t-\Delta t}^{t} \theta(\tau) \partial \tau
$$


Because $\Theta(t)$ is a continuous function, $h^{*}(t)$ itself is also continuous, and for every observation of $h(t)$ a sample of the residual series $r(t)$ can be obtained. Next, the noise model (Equation 7.3) is evaluated in order to obtain a series of innovations $v(t)$. Following Von Asmuth et al. (2002), to evaluate the noise model without having to use a Kalman filter (which is computationally expensive) we will derive a direct relation between the residuals $r(t)$ and the innovations $v(t)$. Consider the series $v(t)$ as the nonequidistantly sampled changes in the solution to the stochastic integral describing the residual series

$$
v(t)=\int_{t-\Delta t}^{t} \phi(t-\tau) \partial W(\tau)
$$

With $\emptyset(t)$ from Equation 7.5 as the noise IR function, we can rewrite Equation 7.3 as

$$
r(t)=e^{-\alpha \Delta t} r(t-\Delta t)+\int_{-\infty} \sqrt{2 \alpha \sigma_{r}^{2}} e^{-\alpha(t-\tau)} \partial W(\tau)
$$

which is known as an Ornstein-Uhlenbeck process (Uhlenbeck and Ornstein, 1930; Gardiner, 1994). Combining Equation 7.9 and Equation 7.10, we obtain the innovation series calculated from the available data:

$$
v(t)=r(t)-e^{-\alpha \Delta t} r(t-\Delta t)
$$

Subsequently, an estimative of the model parameters set $\beta=(A$, a, $n, \alpha)$ is made with the aid of a Levenberg-Marquardt algorithm, which numerically minimizes a weighted least-squares criterion based on the likelihood function of the noise model. Finally, the accuracy and validity of the model are checked using the auto- and cross-correlation functions of the innovations, the covariance matrix of the model parameters, and the variance of the IR functions. For a complete overview of the PIRFICT model formulation, applications, and study cases, refer to Von Asmuth and Maas (2001), Von Asmuth et al. (2002), Von Asmuth and Knotters (2004), and Von Asmuth and Bierkens (2005).

The PIRFICT model was applied in this study because the model can describe a wide range of response times with differences in sampling frequency between input series and output series. For the Cerrado situation it is particularly interesting because different behaviors of water tables can be found even in small catchments. Being the most important driving forces of water table fluctuation, precipitation and evapotranspiration are incorporated as exogenous variables into the model.

\subsubsection{Uncertainty Measures-Simulating Water Table Depths}

Time series models using precipitation surplus/deficit as the input variables, calibrated on time series of water table depths with limited years, enable us to simulate 
series of extensive length (Knotters and Van Walsum, 1997). From extensive series, statistics of WTD can be estimated. These will represent the prevailing hydrological and climatic conditions rather than specific meteorological circumstances during the monitoring period of water table depths.

The simulation of water table depths presented here is based on a time frequency filtering of the PIRFICT model performed as a convolution in the time frequency domain. This operation considers the shape of the PIII df adjusted from the parameters of each model. Since water table depths indicate the output of a time varying system, the interaction of the precipitation input signal and the system can be regarded as an operation in the time frequency domain between the time frequency expansion of the signal and the time frequency response of the system.

These models contain a dynamic component, describing the dynamic relationship between the input and the output, either physically or empirically. But variation of the water table cannot be completely explained from the precipitation and evapotranspiration series. So, the models must contain a noise component, which describes the part of water table fluctuation that cannot be explained with the used physical concepts or empirically from the input series. The unexplained part (noise component) has to be taken into account in the simulation procedure, since we are interested in the statistics of extremes, like the probabilities that critical levels are exceeded. Details about simulation can be found in Hipel and McLeod (1994). Here, we evaluate the uncertainty of the estimations of water table depths simulating 1000 realizations of the PIRFICT model in order to calculate probability distribution functions (PDFs) of the target variable. The uncertainty is taken into account by the probability thresholds established to risk management, generated from the PDFs. The following steps are followed:

- After modeling the relationship between precipitation surplus/deficit and water table depths using the PIRFICT model, series of water table depths are extrapolated to a length of 30 years. It is assumed that the average weather conditions during the last 30 years represent the prevailing climate. As a result, deterministic series of predicted water table depths are generated.

- Realizations of the noise process are generated by stochastic simulation and next added to the deterministic series, resulting in realizations of series of WTD. Realizations of the noise process can be generated either by random sampling from a normal distribution with zero mean and residual variance, or by resampling from the fitted residuals.

- From the previous step, $N$ realizations of the stochastic simulation are generated. With a probability density function of the distribution of water table depths for each $t$ instant, the statistics representing the prevailing hydrologic conditions can be calculated.

In this study, we applied random sampling from a normal distribution. We decided to calculate statistics about WTD for a $t$ that equals October 1 . This is a reasonable date at which cultivations in the Cerrado region start. The rainy season usually starts around this period. Farmers start cultivations just after the first rains of the season. 
To enable risk management of water table depths for October 1 we calculated two levels of probability. First, a 5\% probability level was considered as a measure for risk of water shortage. With this results, we can say that the area has just 5\% probability to have water levels deeper than the values of the resulting map, and 95\% higher water levels. The limits established for risks of water shortage at October 1 were the depths of the wells, with dry wells characterizing a scenario of water shortage in the area. It can be a problem during the beginning of the plants' development, affecting water availability and resulting in production losses.

Second, a 95\% probability level was considered as a measure for risk of shallow water tables. Shallow water tables can be a problem in the beginning of the rainy season because it can make machinery impossible, affecting plowing and planting operations. It can also influence soil conditions, decreasing soil redox potential, AU:OK as
edited? increasing $\mathrm{pH}$ in acid soils, and decreasing in alkaline soils and increasing conductivity and ion exchange reactions. These modifications in the system might influence plant growth, by affecting the availability on toxicity of nutrients, regulating uptake in the rhizosfere. With these results, we can say that the area has just 5\% probability of having water levels higher than the values of the resulting map, and $95 \%$ deeper water levels. The limits established for risks of shallow water table depths at October 1 were $0.5 \mathrm{~m}$ below the ground surface.

\subsubsection{Risk Mapping一-Regionalizing Simulated Water Table Depths}

The results of WTD simulations are interpolated spatially using universal kriging (Matheron, 1969; Pebesma, 2004). The use of exhaustive information on elevation is interesting, because it can decrease the variance and the uncertainty in the spatial prediction model. Also, when the ancillary information is physically related to the target variable, it can incorporate physical meaning to the predictions. In our case, areas with relatively low elevation and close to drainage devices present relatively shallow water tables, whereas in areas with relatively high elevation and far from drainage devices, the water table is relatively deep (Furley, 1999).

Incorporating DEM as drift (Odeh et al., 1994; Knotters et al., 1995) in the spatial prediction model works as follows. Let the simulated water table depths be given as $z\left(x_{1}\right), z\left(x_{2}\right), \ldots, z\left(x_{n}\right)$, where $x_{i}$ is a (two-dimensional) well location and $n$ is the number of observations (i.e., $n=37$ ). At a new, unvisited location $x_{0}$ in the area, $z\left(x_{0}\right)$ is predicted by summing the predicted drift and the interpolated residual (Odeh et al., 1994; Hengl et al., 2004):

$$
\hat{z}\left(x_{0}\right)=\hat{m}\left(x_{0}\right)+\hat{e}\left(x_{0}\right)
$$

where the drift $m$ is fitted by linear regression analysis, and the residuals $e$ are interpolated using kriging:

$$
\begin{aligned}
& \hat{z}\left(x_{0}\right)=\sum_{k=0}^{p} \hat{\beta}_{k} \cdot q_{k}\left(x_{0}\right)+\sum_{i=1}^{n} w_{i}\left(x_{0}\right) \cdot e\left(x_{i}\right) ; \\
& q_{0}\left(x_{0}\right)=1
\end{aligned}
$$


Here, the $\beta_{k}$ are estimated drift model coefficient $q_{k}\left(x_{0}\right)$ is the $k$ th external explanatory variable (predictor) at location $x_{0}, p$ is the number of predictors, $w_{i}\left(x_{0}\right)$ are the kriging weights, and $e\left(x_{i}\right)$ are the zero-mean regression residuals. In this case, for WTD, the model was formulated as follows:

$$
\operatorname{WTD}\left(x_{0}\right)=\beta_{0}+\beta_{1} \cdot E V\left(x_{0}\right)+e\left(x_{0}\right)
$$

where $E V$ is the elevation value for each location and $e$ is a zero-mean spatially correlated residual. Its spatial correlation structure is characterized by a semivariogram.

\subsubsection{Summary of the Method}

The methods described in Subsection 7.2.2 to Subsection 7.2.4 are now summarized as follows:

1. Calibrate the PIRFICT model.

2. Stochastically simulate the WTD series by using the PIRFICT model $(N=$ 1000) and input series of 30 years' length.

3. Pick all selected date (October 1) values of WTD generated by stochastic simulation.

4. Create a probability distribution function (PDF) of these values.

5. Select the percentile values (5th and 95th) for the WTD.

6. Repeat steps $1-5$ for all wells.

7. Model the spatial structure of the percentile values with geostatistics techniques.

8. Finally, use these values of the WTD to create risk maps of water levels that could be exceeded at the selected date with 5 and $95 \%$ probability

\subsection{RESULTS}

\subsubsection{Time Series Modeling}

Due to spatially varying hydrological conditions, a wide range of calibration results was found for the 37 observed wells. Table 7.1 summarizes the results of the time series modeling.

The percentage of variance indicated a good fit of the PIRFICT model to the data. Low percentages might be caused by errors in the data or lack of data, or possibly because other inputs that affect the groundwater dynamics are not incorporated into the model (Von Asmuth et al., 2002). The parameters of the PIRFICT model are summarized in Table 7.2. Some problems with the calibration were diagnosed by checking the impulse response function for each well. After several calibrations, the RMSE and RMSI values were the minimum founded for each well.

The physical plausibility of the results of a TFN model can be judged, for instance, by checking the IR functions. It is equivalent to the cross-correlation function. We check if the memory of the hydrological system, indicated by the time lag where the IR function approximates to zero, is covered by the monitoring period (De Gruijter 
TABLE 7.1

Summary of the Statistics of PIRFICT Model Calibration

$\begin{array}{lccccccc} & \text { Min } & \mathbf{1}^{\text {st }} \mathbf{Q} & \text { Med } & 3^{\text {rd }} \mathbf{Q} & \text { Max } & \text { Mean } & \text { SD } \\ \mathrm{R}_{\text {adj }}^{2} & 57.68 & 76.16 & 82.91 & 88.04 & 95.45 & 81.85 & 9.21 \\ \text { RMSE } & 0.080 & 0.350 & 0.701 & 0.904 & 1.886 & 0.680 & 0.41 \\ \text { RMSI } & 0.072 & 0.313 & 0.555 & 0.750 & 1.433 & 0.552 & 0.32\end{array}$

Note: $\quad R_{\text {adj }}^{2}=$ percentage of explained variance; $\mathrm{RMSE}=$ root mean squared error (meters); RMSI = root mean squared innovation (meters); Min = minimum; $1^{\text {st }} \mathrm{Q}=$ first quartile; Med = median; $3^{\text {rd }} \mathrm{Q}=$ third quartile; Max = maximum $; \mathrm{SD}=$ standard deviation.

\section{TABLE 7.2}

\section{Summary of Calibrated Parameters of the PIRFICT Model}

$\begin{array}{lccccccc} & \text { Min } & \mathbf{1}^{\text {st }} \mathbf{Q} & \text { Med } & \text { 3 }^{\text {rd }} \mathbf{Q} & \text { Max } & \text { Mean } & \text { SD } \\ A & 54.8 & 770.9 & 1250 & 1955 & 6160 & 1711.3 & 705.5 \\ \mathrm{a} & 0.001 & 0.004 & 0.007 & 0.011 & 0.162 & 0.013 & 0.01 \\ n & 0.49 & 1.05 & 1.30 & 1.72 & 2.86 & 1.43 & 0.24 \\ \mathrm{E} & -5.85 & -0.94 & 0.88 & 1.65 & 2.58 & 0.24 & 0.93 \\ \alpha & 5.92 & 22.03 & 32.24 & 47.69 & 95.50 & 38.60 & 14.73 \\ \mathrm{IR} & 0 & 218 & 600 & 900 & 2200 & 656.58 & 570.6 \\ \mathrm{LD} & -50.6 & -13.9 & -7.37 & -1.39 & 0.0 & -10.16 & 11.97\end{array}$

Note: $A=$ drainage resistance (days); a = decay rate (1/days); $n=$ convection time (days); $\mathrm{E}=$ reduction factor $(-) ; \alpha=$ decay or memory of the white noise process $(-) ; \mathrm{IR}=$ impulse response (days); $\mathrm{LD}=$ local drainage base (meters); Min = minimum; $1^{\text {st }} \mathrm{Q}=$ first quartile; Med = median; $3^{\text {rd }} \mathrm{Q}=$ third quartile; Max $=$ maximum; $\mathrm{SD}=$ standard deviation.

et al., 2006). A lack of relationship between the input series and the observed water table depths was found for three wells. The monitoring period apparently was not long enough to characterize the long memories of the hydrological system in these sites at the Jardim river area.

Parameter $A$ is related to the shape of the IR function. Large values of $A$ were calibrated to series at sites where a large fluctuation of the water table level was observed. From a mathematical point of view, these sites have large pulses from the signal of the input in the system. Some attention should be paid to parameter $E$, the reduction factor of evapotranspiration. This value should be between 0 and 1 . For some wells we found estimates of $E$ that are not realistic, like negative values. One reason could be that the climate station, located around $10 \mathrm{~km}$ outside the study area, does not represent the meteorological circumstances at all well locations. Another reason might be in the large temporal variation of land use, which makes these parameters difficult to estimate. 
Stochastic simulation with the PIRFICT model was performed for the 34 wells, which remained after inspection of the results. For seven wells the simulation results indicated that the stationary conditions were not met. The distribution functions of the simulated WTD for these wells were bimodal. These wells were excluded from interpolation. Possibly the relatively short length of the water table time series did not completely cover the response time of the hydrological system. For example, the dry years of 2001, 2002, and 2003 might have a long-term effect on water tables in systems with long memories. The precipitation in these years was 24.4, 41.02, and $33.2 \%$ less than the annual average over the last 30 years, respectively. This effect acts different over the basin, due the presence of different geological systems (Lousada, 2005). Continuing monitoring of theWTD would enable us to clarify these questions (De Gruijter et al., 2006). For the remaining 27 wells, the distribution function of the WTD for October 1 was created from the simulated data. The WTDs that are expected to be exceeded with 5 and $95 \%$ probability at October 1 were used for spatial interpolation.

\subsubsection{SPATIAL INTERPOLATION}

The spatial dependence of the WTDs that are exceeded with 5 and $95 \%$ probability at October 1 was modeled by semivariograms (Figure 7.2). The alternative to using ancillary information on spatial prediction was taken, once the number of estimation points was sensibly reduced. Including elevation as a spatial drift into the geostatistical model caused a decrease in the semivariance.

The spatial dependence at short distances is poorly estimated because of the small number of observation wells that are fairly uniformly spread across the area. The nugget parameter of the semivariogram reflects the measurement precision of the WTD and the short-distance spatial variation in the WTDs.

The semivariogram fitted for WTDs that are exceeded with $95 \%$ probability, including a trend that depends on elevation, was used on UK estimation. The resulting map shows WTDs that could be exceeded with 95\% probability at October 1. The probability of having lower (deeper) values than these in the maps is just $5 \%$. Figure 7.3 gives these results for October 1 of any future year and the corresponding kriging variance.
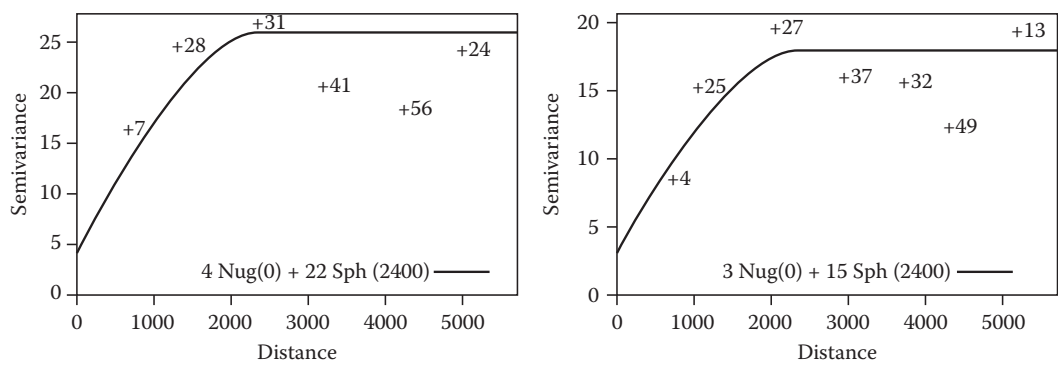

FIGURE 7.2 Semivariograms fitted for WTDs that are exceeded at October 1 with $95 \%$ (left) and 5\% (right) probability, including a trend that depends on elevation. 

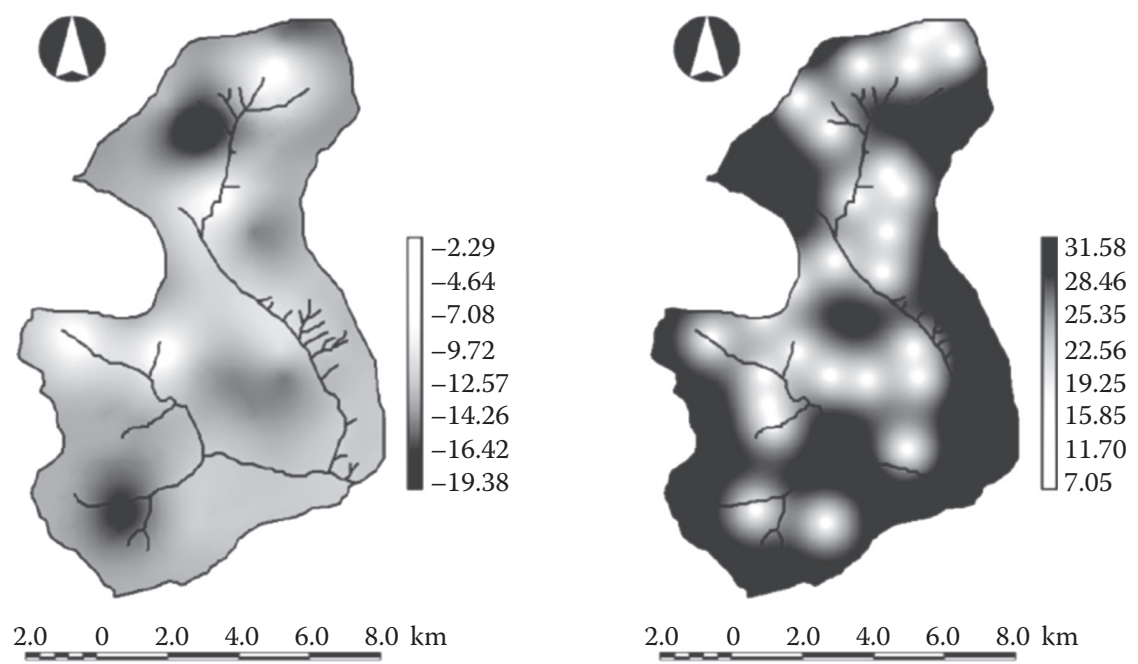

FIGURE 7.3 Map of WTDs (meters) that will be exceeded with 95\% probability at Oct 1 (right) and the corresponding kriging variance (left).
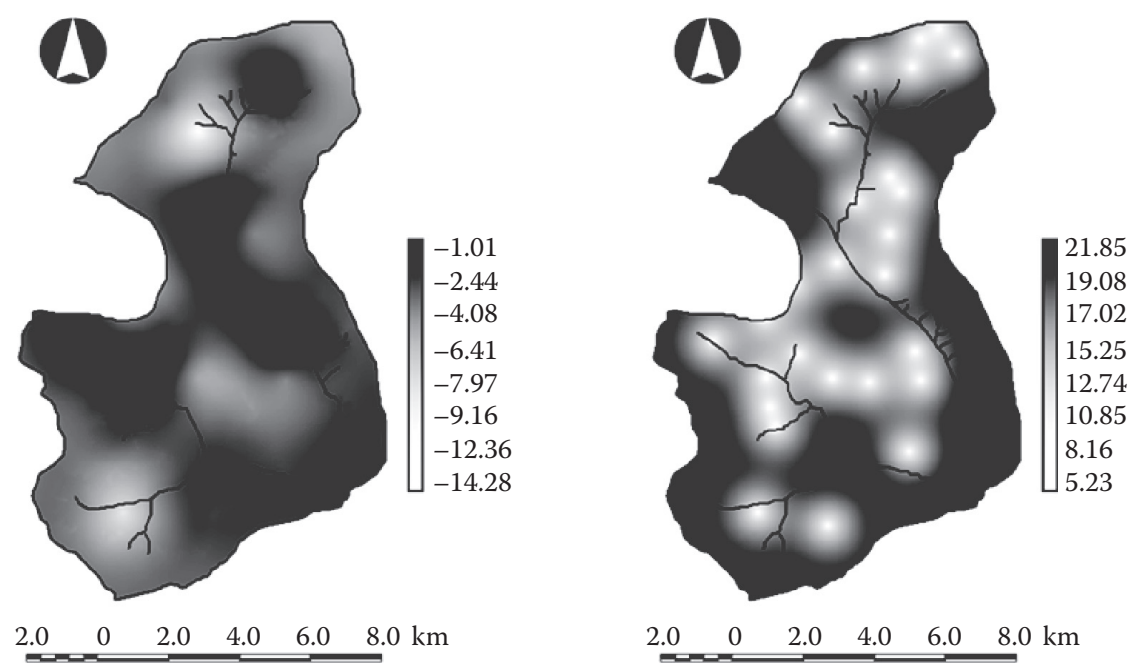

FIGURE 7.4 Map of WTDs levels (meters) that will be exceeded with 5\% probability at Oct 1 (right) and the corresponding kriging variance (left).

Figure 7.4 gives the results of mapping WTDs with a confident level of $95 \%$, including a trend that depends on using elevation and the corresponding kriging variances.

The UK resulted in maps with a physical meaning related to the local drainage. These maps were applied to quantify the risks on water management.

We compared the map of WTDs that will be exceeded with $95 \%$ probability with a map of estimated depth of wells as limit for water shortage. It indicated that no problems with deep water levels will occur at October 1, because no well can be 
dry with these levels. The same analysis was made for the map of WTDs that will be exceeded with $5 \%$ probability with a $0.5 \mathrm{~m}$ limit map for shallow water table depths. The risk that these occur at October 1 is negligible.

\subsubsection{Cross-Validation}

The results of spatial interpolation were evaluated by cross-validation. Table 7.3 and Table 7.4 give the results. The SD values of the observations are much higher than those of predictions, indicating that the interpolation values are smooth (e.g., 4.86 vs. 1.79 in Table 7.3 or 4.16 vs. 1.83 in Table 7.4). The errors can be explained from

TABLE 7.3

Cross-Validation for the Spatial Interpolations of WTDs that Are Exceeded with 95\% Probability at Oct 1

Obs. Pred. Pred.-Obs. Pred. SD Z-Score

$\begin{array}{lrrrrr}\text { Min } & -21.36 & -14.80 & -10.25 & 3.99 & -2.24 \\ 1^{\text {st }} \mathrm{Q} & -11.83 & -10.22 & -1.99 & 4.54 & -0.42 \\ \text { Med } & -8.80 & -9.28 & 1.13 & 4.77 & 0.25 \\ 3^{\text {rd }} \mathrm{Q} & -7.79 & -8.18 & 2.67 & 5.04 & 0.59 \\ \text { Max } & -0.72 & -5.91 & 12.35 & 5.55 & 2.44 \\ \text { Mean } & -9.37 & -9.43 & -0.05 & 4.78 & -0.006 \\ \text { SD } & 4.86 & 1.79 & 5.49 & 0.42 & 1.12\end{array}$

Note: $\quad$ Pred. $=$ predicted $;$ Obs. $=$ observed $($ meters $) ; Z$-score $=($ Pred.-Obs. $) /$ kriging variance $(-)$; Min $=$ minimum; 1 st $Q=$ first quartile; 3rd $Q=$ third quartile; $\operatorname{Max}=$ maximum; $\mathrm{SD}=$ standard deviation.

\section{TABLE 7.4}

Cross-Validation for the Spatial Interpolations of WTDs that Are Exceeded with 5\% Probability at Oct 1

$\begin{array}{lrrccc} & \text { Obs. } & \text { Pred. } & \text { Pred.-Obs. } & \text { Pred. SD } & \text { Z-Score } \\ \text { Min } & -16.04 & -10.73 & -7.04 & 3.36 & -1.84 \\ 1^{\text {st }} \mathrm{Q} & -8.42 & -6.51 & -3.16 & 3.79 & -0.86 \\ \text { Med } & -5.62 & -5.82 & 0.78 & 3.98 & 0.21 \\ 3^{\text {rd }} \mathrm{Q} & -2.62 & -4.84 & 2.24 & 4.20 & 0.55 \\ \text { Max } & 0.14 & -1.61 & 10.23 & 4.62 & 2.43 \\ \text { Mean } & -5.75 & -5.71 & 0.04 & 3.99 & 0.005 \\ \text { SD } & 4.16 & 1.83 & 4.57 & 0.34 & 1.12\end{array}$

Note: $\quad$ Pred. $=$ predicted; Obs. $=$ observed $($ meters $) ; Z$-score $=($ Pred. - Obs. $) /$ kriging variance $(-)$; Min $=$ minimum; 1 st $Q=$ first quartile; 3 rd $Q=$ third quartile; $\mathrm{Max}=$ maximum; $\mathrm{SD}=$ standard deviation. 
uncertainty about the calibrated models, a poor relationship between elevation and WTD, and from a poor spatial correlation structure in both kriging models.

Predictions on Table 7.3 and Table 7.4 had the mean WTD value respected and indicate small mean interpolation errors (-0.05 and $0.04 \mathrm{~m}$, respectively). The mean and standard deviation of the $Z$-score had values close to zero and one, respectively, which indicates a good performance of the kriging systems.

\subsection{CONCLUSION}

Time series modeling using the PIRFICTmodel was efficient to model a wide range of different responses of the hydrological system presented over the basin. Policy makers can and should use these results to optimize water use and to regulate the competing claims for water resources that often occur between small farmers, big farmers with irrigated crops, and water withdrawal for human use. However, the results reflect uncertainties from different sources: uncertainties related to the data (observed WTD, climatic database, DEM), and uncertainty associated with time series modeling and with the model of spatial variation.

The quality of the map was restricted by the effects of the relatively short time series that did not satisfactorily characterize the long memory systems. The quality of the time series models depends on both sampling frequency and the length of the series. The quality of the model of spatial structure depends on the number and the configurations the of well locations. The use of DEM as ancillary information slightly improved the quality of the final risk maps.

For the chosen date, October 1, there is a negligible risk of water shortage and shallow water table depths that could affect agriculture in some way. The analysis should be extended to other dates and periods that are critical to water supply. The method presented in this study enables this extension.

Given the long memories in the hydrological system of the study area, we recommend continued monitoring of water table depths in order to obtain more reliable results in the future.

\section{ACKNOWLEDGMENTS}

The first author is grateful to CAPES Foundation/Brazil (Foundation for the Coordination of Higher Education and Graduating Training) and to WIMEK (Wageningen Institute for Environment and Climate Research) for their financial support during his studies at ALTERRA, Wageningen, The Netherlands. We are also grateful to Dr. Suzana Druck (EMBRAPA/Cerrados-Brazilian Agricultural Research Corporation) for the use of this database (PRODETAB-Agricultural Technology Development Project for Brazil).

\section{REFERENCES}

Abramowitz, M. and I. A. Stegun. 1964. Handbook of mathematical functions. New York: Dover Publications Inc.

Box, G. E. P. and G. M. Jenkins. 1976. Time series analysis: forecasting and control. San Francisco: Holden-Day. 
De Gruijter, J. J., D. J. Brus, M. F. P. Bierkens, and M. Knotters. 2006. Sampling for natural resource monitoring. Berlin: Springer-Verlag.

Furley, P. A. 1999. The nature and diversity of neotropical savannah vegetation with particular reference to the Brazilian Cerrados. Global Ecol. Biogeogr. 8:223-241.

Gardiner, C. W. 1994. Handbook of stochastic methods. New York: Springer-Velag.

Hengl, T., G. B. M. Heuvelink, and A. Stein. 2004. A generic framework for spatial prediction of soil properties based on regression-kriging. Geoderma 120:75-93.

Hipel, K. W. and A. I. McLeod. 1994. Time series modelling of water resources and environmental systems. Amsterdam: Elsevier.

Jepson, W. 2005. A disappearing bioma? Reconsidering land-cover change in the Brazilian savanna. Geographical J. 2:99-111.

Klink, C. A. and A. G. Moreira. 2002. Past and current human occupation and land-use. In The Cerrado of Brazil: Ecology and Natural History of a Neotropical Savannah, P. S. Oliveira and R. J. Marquis, Eds., pp. 69-88. New York: Columbia University Press.

Knotters, M. and M. F. P. Bierkens. 2001. Predicting water table depths in space and time using a regioinalised time series model. Geoderma 103:51-77.

Knotters, M. and M. F. P. Bierkens. 2000. Physical basis of time series models for water table depths. Water Resour. Res. 36:181-188.

Knotters, M. and P. E. V. Van Walsum. 1997. Estimating fluctuation quantities from time series of water-table depths using models with a stochastic component. J. Hydrol. 197:25-46.

Knotters, M., D. J. Brus, and J. H. Oude Voshaar. 1995. A comparation of kriging, co-kriging and kriging combined with regression for spatial interpolation of horizont depth with censored observations. Geoderma 67:227-246.

Lousada, E. O. 2005. Hydrogeologic and isotopic studies in the Distrito Federal: conceptual flow models. PhD diss., Brasília Univ.

Matheron, G. 1969. Le krigeage universel. Cachiers du Centre de Morphologie Mathematique. Fontainebleau: Ecole des Mines de Paris.

Nash, J. E. 1958. Determining runoff from rainfall. Proc. Inst. Civ. Eng. 10:163-184.

Odeh, I., A. McBratney, and D. Chittleborough. 1994. Spatial prediction of soil properties from landform attributes derived from a digital elevation model. Geoderma 63:197-214.

Oliveira, R. S., L. Bezerra, E. A. Davidson, F. Pinto, C. A. Klink, D. C. Nepstad, and A. Moreira. 2005. Deep root function in soil water dynamics in cerrado savannas of central Brazil. Functional Ecology 19:574-581.

Pebesma, E. J. 2004. Multivariable geostatistics in S: the Gstat package. Comput. Geosci. 30: 683-691.

Tankersley, C. D. and W. D. Graham. 1994. Development of an optimal control system for maintaining minimum groundwater levels. Water Resour. Res. 30:3171-3181.

Uhlenbeck, G. E., and L. S. Ornstein. 1930. On the theory of Brownian motion. Physical Review 36:823-841.

Van Geer, F. C. and A. F. Zuur. 1997. An extension of Box-Jenkins transfer/noise models for spatial interpolation of groundwater head series. J. Hydrol. 192:65-80.

Von Asmuth, J. R. and M. F. P. Bierkens. 2005. Modelling irregularly spaced residual series as a continuous stochastic process. Water Resour. Res. 41:W12404.

Von Asmuth, J. R., and M. Knotters. 2004. Characterising groundwater dynamics based on a system identification approach. J. Hydrol. 296:118-34.

Von Asmuth, J. R. and C. Maas. 2001, The method of impulse response moments: a new method integrating time series, groundwater and eco-hydrological modelling. In Impact of human activity on groundwater dynamics, J. C. Geherls, N. E. Peters, E. Hoehn, et al., Eds., pp. 51-58. Wallingford: IAHS Publication. 
Von Asmuth, J. R., M. F. P. Bierkens, and C. Maas. 2002. Transfer function noise modelling in continuous time using predefined impulse response functions. Water Resour. Res. 38(12):23.1-23.12.

Ziemer, R. E., W. H. Tranter, and D. R. Fannin. 1998. Signals and systems: continuous and discrete. Upper Saddle River, NJ: Prentice-Hall. 
